\title{
STUDY OF CARDIOVASCULAR INVOLVEMENT IN ESRD PATIENTS IN A TERTIARY CARE CENTER
}

\author{
Karunakar Das ${ }^{1}$, Aswini Kumar Sahoo 2
}

${ }_{1}^{1}$ Associate Professor, Department of General Medicine, Maharajah's Institute of Medical Sciences, Vizianagaram, Andhra Pradesh. ${ }^{2}$ Associate Professor, Department of General Medicine, Maharajah's Institute of Medical Sciences, Vizianagaram, Andhra Pradesh.

\begin{abstract}
The increased prevalence of vascular disease in CKD patients derives from both traditional and CKD-related risk factors. Traditional risk factors include hypertension, hypervolemia, dyslipidemia, sympathetic over-activity and hyperhomocysteinemia. The CKD-related risk factors comprise anemia, hyper-phosphatemia, hyper-parathyroidism and generalized inflammation. Other abnormalities seen in CKD may augment myocardial ischemia including left ventricular hypertrophy and microvascular disease. Patients with chronic kidney disease are at significantly increased risk for both morbidity and mortality from cardiovascular disease. Diabetes (36\%) was leading cause of end stage renal disease followed by hypertension (20.5\%). Symptoms and signs related to cardiovascular system are evident in majority of patients. Mean serum creatinine level was $10.15 \pm 4.95 \mathrm{mg} / \mathrm{dl}$. Mean serum cholesterol level was 205.13 \pm 48.82 ; it was elevated in $58 \%$ of patients. Mean serum triglyceride level was $180.79 \pm 39.61$; it was elevated in $82.5 \%$ of patients. Mean serum LDL level was $120.37 \pm 34.49$; it was elevated in $88 \%$ of patients. Mean serum HDL level was $35.87 \pm 6$; it was decreased in $77 \%$ of ESRD patients. X-ray finding showed cardiomegaly in 34.55 patients; pulmonary edema was present in $25.5 \%$ and pleural effusion was noted in $18 \%$ patients clinically evident cardiovascular abnormality in ESRD was observed in majority of patients. Left ventricle dysfunction was the commonest cardiovascular abnormality. Diastolic function was deranged in more number of patients compared to systolic function suggesting that diastolic dysfunction was first to appear in patients with ESRD. Major contributing factors for left ventricle hypertrophy and diastolic dysfunction were hypertension and anemia. Major contributing factor for systolic dysfunction was due to regional wall motion abnormality due to ischemic heart disease. Echocardiography was more sensitive in detecting LVH, diastolic dysfunction and minimal pericardial effusion prior to clinical detection.
\end{abstract}

\section{KEYWORDS}

CKD, ESRD, Cardiovascular Involvement.

HOW TO CITE THIS ARTICLE: Das K, Sahoo AK. Study of cardiovascular involvement in ESRD patients in a tertiary care center. J. Evolution Med. Dent. Sci. 2016;5(15):680-682, DOI: 10.14260/jemds/2016/156

\section{INTRODUCTION}

Patients with chronic kidney disease are at increased risk for both morbidity and mortality from cardiovascular disease. Dialysis patients have 10-30 fold increase risk for cardiovascular mortality compared to general population and is the single most important cause of death among patients receiving long-term dialysis accounting for $44 \%$ of overall mortality. ${ }^{1}$ The magnitude of the problem has more apparent as patients survive longer on maintenance hemodialysis. Coronary artery disease, congestive heart failure and pericardial disease are common manifestations of major cardiovascular manifestations in the end stage renal disease.

Premature cardiovascular disease is a significant cause of morbidity and mortality among patients with CRF. Premature atherosclerotic coronary disease is driven by multiple risk factors including dyslipidemia and oxidative stress. Four main structural abnormalities of the heart have been described in patients with CRF. LV hypertrophy, expansion of the nonvascular cardiac interstitium leading to inter-myocardiocytic fibrosis, changes in vascular architecture and myocardial calcification. All these abnormalities promote systolic as well as diastolic LV dysfunction, which predisposes to symptomatic heart failure, which is a factor for premature death.

Financial or Other, Competing Interest: None

Submission 05-01-2016, Peer Review 03-02-2016,

Acceptance 08-02-2016, Published 19-02-2016.

Corresponding Author:

Dr. Aswini Kumar Sahoo,

Or. No. E-3, Doctor's Quarter, MIMS, Nellimarla,

Vizianagaram-535217, Andhra Pradesh.

E-mail: sahoo.aswini@gmail.com

DOI: $10.14260 /$ jemds $/ 2016 / 156$
Prospective cohort studies have demonstrated that Left Ventricular Hypertrophy (LVH) is the most frequent cardiac abnormality in ESRD with $74.5 \%$ of patients demonstrating LVH by the time of starting dialysis. ${ }^{2}$ This compares to a prevalence of $20 \%$ in the general population. ${ }^{3}$ various diagnostic modalities, both invasive and non-invasive such as electrocardiography, echocardiography and chest X-ray are utilized for diagnosing left ventricular hypertrophy and dysfunction.

\section{MATERIALS AND METHODS}

Two hundred patients of chronic kidney disease who were admitted in the medical wards and dialysis unit of Maharajahs Institute of Medical Sciences, Vizianagaram, during Jan 2013 to June 2014. Patients with chronic kidney disease with stage 3 , stage 4 and stage 5 exclusion criteria, 2 chronic Alcoholics, Acute renal failure patients.

Detailed history; General and Systemic examination; Investigations like Hemoglobin, blood Sugar, Urea, Creatinine, serum Calcium, Phosphorus, Sr. Electrolytes: Sodium, Potassium, Lipid profile, Serum protein, 24-hour urine protein estimation. Renal biopsy to be done if etiology is not clear. 


\section{OBSERVATIONS AND RESULTS}

\begin{tabular}{|c|c|c|}
\hline Etiology of CRF & $\begin{array}{l}\text { No. of } \\
\text { Cases }\end{array}$ & $\begin{array}{c}\text { Percentage } \\
(\%)\end{array}$ \\
\hline Diabetes & 72 & 36.0 \\
\hline Hypertension & 41 & 20.5 \\
\hline $\begin{array}{c}\text { Diabetes/ } \\
\text { Hypertension }\end{array}$ & 33 & 16.5 \\
\hline $\begin{array}{c}\text { Chronic } \\
\text { glomerulonephritis }\end{array}$ & 21 & 10.5 \\
\hline $\begin{array}{c}\text { Analgesic } \\
\text { nephropathy }\end{array}$ & 8 & 4.0 \\
\hline $\begin{array}{l}\text { Polycystic kidney } \\
\text { disease }\end{array}$ & 15 & 7.5 \\
\hline Unknown & 10 & 5.0 \\
\hline Total & 200 & 100 \\
\hline
\end{tabular}

Diabetes (36\%) was leading cause of end stage renal disease.

\begin{tabular}{|c|c|c|}
\hline Symptoms & $\begin{array}{c}\text { No. of } \\
\text { Cases }\end{array}$ & Percentage (\%) \\
\hline Breathlessness & 170 & 85.0 \\
\hline Swelling of legs/face & 144 & 72.0 \\
\hline Easy fatigability & 95 & 47.5 \\
\hline Chest pain & 28 & 14.0 \\
\hline Palpitation & 20 & 10.0 \\
\hline Giddiness & 50 & 25.0 \\
\hline
\end{tabular}

Table 2: Symptoms suggesting cardiovascular involvement of ESRD study cases

The most common symptom in ESRD patients was breathlessness (85.5\%).

\begin{tabular}{|c|c|c|}
\hline Signs & No. of Cases & $\begin{array}{c}\text { Percentage } \\
\%\end{array}$ \\
\hline Pallor & 200 & 100.0 \\
\hline Oedema & 149 & 74.5 \\
\hline Hypertension & 140 & 70.0 \\
\hline JVP & 78 & 39.0 \\
\hline Pericardial rub & 29 & 14.5 \\
\hline Murmur & 29 & 14.5 \\
\hline $\begin{array}{c}\text { Bilateral pleural } \\
\text { effusion }\end{array}$ & 33 & 16.5 \\
\hline $\begin{array}{c}\text { Table 3: Signs suggesting cardiovascular involvement } \\
\text { of ESRD study cases }\end{array}$ \\
\hline
\end{tabular}

Pallor is included in signs suggesting of cardiovascular involvement; it is indirectly related and was most common finding. Edema (75.5\%), HTN (70\%), raised JVP (39\%), pericarditis $(14 \%)$, murmur $(14.5 \%)$ and bilateral pleural effusion (16\%) were present in ESRD patients.

\section{DISCUSSION}

In this study, diabetes (36\%) was the leading cause of end stage renal disease followed by hypertension (20.5\%), both diabetes and hypertension (16.5\%), chronic glomerulonephritis (10.5\%), polycystic kidney disease (7.5\%), analgesic nephropathy (5\%) which is consistent with study done by Sanjay Kumar, et al. (2005). ${ }^{4}$ The mean serum cholesterol level was 205.13+/-48.82. Serum cholesterol level was elevated in $58 \%$ of patients. Mean serum triglyceride level was $180.79+/-39.61$; it was elevated in $82.5 \%$ of patients.
Mean serum LDL level was $120.37+/-34.49$; it was elevated in $88 \%$ of patients. Mean serum HDL level was $35.87+/-6.00$; it was decreased in $77.0 \%$ of patients. The findings were consistent with study done by Daniel J Brotman et al. (2010). ${ }^{5}$ Chi-yuan Hsu et al. (2009). ${ }^{6}$ Beman-ali et al. (2000). ${ }^{7}$ and Arsalan N Habib, et al. (2006). ${ }^{8}$

The X-ray findings showed cardiomegaly in $34.5 \%$ patients; pulmonary edema was present in $25.5 \%$ and pleural effusion was noted in $16.5 \%$ patients, which was consistent with study done by Debasish Banerjee et al. (2007). ${ }^{9}$ In this study ECG changes were tachycardia (48.5\%), left ventricular hypertrophy (64\%), ST-T changes (29\%), ventricular ectopics $(8.5 \%)$ complete heart block $(1.5 \%)$ and low voltage pattern (5.5\%) in pericardial effusion, tall $\mathrm{T}$-wave $(37.5 \%)$ and ventricular tachycardia $(1.5 \%)$ in hyperkalemia, QT prolongation $(6.0 \%)$ patients, which is consistent with study done by Roy et al. (1994).10 There is statistically significant association between the clinical findings of ECG and patients having hypertension, since $\mathrm{p}<0.05$ except for LVH.

In the present study LVH was present in $87.15 \%$, diastolic dysfunction was present in $72.1 \%$ (abnormal E/A ratio). Systolic dysfunction (EF <60\%) was present in $29.3 \%$ and pericardial effusion observed in $16.3 \%$ hypertensive patients. In normotensive group LVH was present in $45 \%$, diastolic dysfunction in $45 \%$ and systolic dysfunction in $15 \%$, pericardial effusion was observed in $15 \%$ patients. There is statistically significant association between the clinical findings of 2D Echo and patients having hypertension in cases of LVH, RWMA, decreased EF and abnormal E/A ratio parameters since $p<0.05$ and $<0.01$ respectively. For rest of findings, no significant association observed. But hypertensive group is dominant in case of remaining findings than normotensive group, i.e. Proportion of patients is more in hypertensive group than normotensive group for each remaining parameter. The above findings were consistent with study done by Robert N. Foley et al. (1995). ${ }^{2}$ NP Singh et al. (2000). ${ }^{11}$ Patrick $S$ et al. (1999). ${ }^{12}$ Wang et al. (2003). ${ }^{13}$

\section{CONCLUSION}

Patients with chronic kidney disease are at significantly increased risk for cardiovascular disease and sudden cardiac death. Early attention to be given to all risk factor to decrease morbidity and mortality.

\section{REFERENCES}

1. Levey AS, Andreoli SP, DuBose T, et al. CKD; common, harmful and treatable - World Kidney Day 2007. Am J Kidney Dis 2007;49:175-9.

2. Foley RN, Parfrey PS, Harnett JD, et al. Clinical and echocardiographic disease in patients starting end-stage renal disease therapy. Kidney Int 1995;47:186-92.

3. Levy D, Garrison RJ, Savage DD, et al. Prognostic determinations of echocardiographically determined left ventricular mass in the Framingham heart study. N Engl J Med 1990;32:1561-1566.

4. Agarwal SK, Dash SC, Irshad M, et al. Prevalence of chronic renal failure in adults in Delhi, India. Nephrol Dial Transplant 2005;20(8):1638-1642.

5. Brotman DJ, Bash LD, Qayyum R, et al. Heart rate variability predicts ESRD and CKD-related hospitalization. J Am Soc Nephrol 2010;21:1560-1570. 
6. Hsu CY, Iribarren C, McCulloch CE, et al. Risk factors for end-stage renal disease: 25-year follow-up. Arch Intern Med 2009;169:342-350.

7. Beman-ali Jalali-khanabadi, Hassan Mozaffari, MohamadHosain Dashti. Assessment of serum lipoprotein (a) in patients with end-stage renal disease. Medical Journal of Islamic Academy of Sciences 13:3-2000, 135-138.

8. Habib AN, Baird BC, Leypoldt JK, et al. The association of lipid levels with mortality in patients on chronic peritoneal dialysis. Nephrol Dial Transplant 21, 2006;2881-2892.

9. Banerjee D, Ma JZ, Collins AJ, et al. Long-term survival of incident hemodialysis patients who are hospitalized for congestive heart failure, pulmonary edema or fluid overload. Clin J Am Soc Nephrol 2007;2:1186-1190.
10. Roy M, Dash LK, Falai RK, et al. Cardiac changes in renal failure. JAPI 1994; Vol 42, no. 12: 1037-41.

11. Singh NP, Chandrasekhar, Nair M. The cardiovascular and hemodynamic effects of erythropoietin in CRF. JAPI 2000; vol 48:3:301-306.

12. Patrick $S$, et al. The clinical epidemiology of cardiac disease in chronic renal failure. J Am Soc Nephro 1999;10:16071615.

13. Wang AY, et al. Cardiac valve calcification as an important predictor for all-cause mortality and cardiovascular mortality in long-term peritoneal dialysis patients: a prospective study. J Am Soc Nephro 2003;14:159-68. 